\title{
Stimulating Effects of KW-5092, a Novel Gastroprokinetic Agent, on the Gastric Emptying, Small Intestinal Propulsion and Colonic Propulsion in Rats
}

\author{
Nobuyuki Kishibayashi and Akira Karasawa \\ Department of Pharmacology, Pharmaceutical Research Laboratories, Kyowa Hakko Kogyo Co., Ltd., \\ 1188 Shimotogari, Nagaizumi-cho, Sunto-gun, Shizuoka 411, Japan \\ Received July 8, $1994 \quad$ Accepted October 21, 1994
}

\begin{abstract}
KW-5092 (\{1-[2-[[[5-(piperidinomethyl)-2-furanyl]methyl]amino]ethyl]-2-imidazolidinylidene $\}$ propanedinitrile fumarate) is a novel gastroprokinetic agent with acetylcholinesterase (AChE) inhibitory activity and acetylcholine $(\mathrm{ACh})$ release facilitatory activity. The present study examined the effects of $\mathrm{KW}-5092$ on gastrointestinal (GI) propulsion in rats. $\mathrm{KW}-5092$ at 1 to $30 \mathrm{mg} / \mathrm{kg}$, p.o. dose-dependently enhanced the gastric emptying, small intestinal propulsion and the proximal and distal colonic propulsion. Metoclopramide, a dopamine $\mathrm{D}_{2}$-receptor antagonist with $\mathrm{ACh}$ release facilitatory activity, dose-dependently enhanced the gastric emptying at 0.03 to $1 \mathrm{mg} / \mathrm{kg}$, p.o., whereas this drug did not affect the small intestinal propulsion, or the proximal and distal colonic propulsion. Neostigmine, an AChE inhibitor, dosedependently enhanced the small intestinal propulsion and the proximal and the distal colonic propulsion at 0.3 to $10 \mathrm{mg} / \mathrm{kg}$, p.o., whereas it delayed the gastric emptying at $10 \mathrm{mg} / \mathrm{kg}$, p.o. The present results demonstrate that $\mathrm{KW}-5092$ enhances the GI propulsion from the stomach to the colon and that metoclopramide or neostigmine enhances only the upper or the lower GI propulsion, respectively. Thus, $\mathrm{KW}-5092$ may be a gastroprokinetic drug of a novel type for the treatment of GI motility dysfunctions in a wide range from the stomach to the colon.
\end{abstract}

Keywords: KW-5092, Metoclopramide, Neostigmine, Gastrointestinal propulsion

Metoclopramide has been demonstrated to possess gastroprokinetic activity and improve the gastrointestinal (GI) motor dysfunctions entailed in gastric stasis, gastroparesis or gastroesophageal reflux disease (1). Its action is ascribed to an antidopaminergic property $(2,3)$ and/or an increase in acetylcholine (ACh) release from postganglionic nerve endings $(4,5)$. On the other hand, neostigmine is a potent acetylcholinesterase (AChE) inhibitor (6) and increases colonic motility in human (7).

KW-5092 (\{1-[2-[[[5-(piperidinomethyl)-2-furanyl]methyl]amino]ethyl]-2-imidazolidinylidene\} propanedinitrile fumarate) is a newly synthesized gastroprokinetic agent. In anesthetized rabbits (8) and in conscious and anesthetized dogs (9), KW-5092 enhanced GI motility, which was examined by a force transducer and was calculated by integrating the area between the baseline and the contractile wave, in a wide range from the gastric antrum to the colon. In the in vitro study, KW-5092 was a potent inhibitor of $\mathrm{AChE}$ derived from rat brain, the inhibitory activity being equipotent to that of neostigmine (8). Moreover, KW-5092 concentration-dependently enhanced the ACh release and the contraction of the isolated longitudinal muscle-myenteric plexus preparation from guinea pig ileum (10). Thus, the stimulation by KW5092 of GI motor activity in vivo as well as in vitro has been ascribed to the $\mathrm{AChE}$ inhibition and the $\mathrm{ACh}$ release facilitation.

If the stimulation of GI motor activity does not lead to peristaltic contractions, GI propulsion may not be enhanced. Since KW-5092 posseses a novel and unique profile as a gastroprokinetic agent, it seemed of interest to examine the effect of this drug on the GI propulsion. Prior to the present paper, however, the effects of $\mathrm{KW}$ 5092 on the GI propulsion have not been reported. In the present study, we investigated the effects of KW-5092 on the gastric emptying, small intestinal propulsion and the colonic propulsion in rats and compared them with those of metoclopramide and neostigmine. 


\section{MATERIALS AND METHODS}

\section{Animals}

Male Sprague-Dawley rats weighing 150 to $250 \mathrm{~g}$ were purchased from Japan SLC, Inc. (Hamamatsu). The animals were maintained on ordinary laboratory chow and tap water ad libitum under a constant 12-hr lightdark cycle.

\section{Drugs}

KW-5092 (\{1-[2-[[[5-(piperidinomethyl)-2-furanyl]methyl]amino]ethyl]-2-imidazolidinylidene propanedinitrile fumarate) and metoclopramide hydrochloride were synthesized in our laboratories. Neostigmine methylsulfate was purchased from Sigma Chemical Co. (St. Louis, MO, USA). Phenol red, charcoal and trichloroacetic acid were purchased from Wako Pure Chemical Industries (Osaka). Arabic gum was purchased from Nacalai Tesque, Inc. (Kyoto). Test drugs were dissolved in saline and were orally administered to rats at a volume of 5 $\mathrm{ml} / \mathrm{kg}$.

\section{Gastric emptying}

The gastric emptying was elicited with a modification of the reported procedure (11). The animals were deprived of food $24 \mathrm{hr}$ prior to the experiment but allowed free access to water until $3 \mathrm{hr}$ before the experiment. A solution of $0.05 \%(\mathrm{w} / \mathrm{v})$ phenol red in aqueous sodium carboxymethyl cellulose $(1.5 \% \mathrm{w} / \mathrm{v})$ was used as a test meal. The test drug was administered p.o. $1 \mathrm{hr}$ before the test meal was given. Fifteen minutes after the test meal was given, the animals were sacrificed by cervical dislocation. The stomach was then exposed by laparotomy and removed. In each experiment, 4 animals treated with vehicle were sacrificed immediately after administration of the meal, and the phenol red content in the stomach was considered as the standard $(100 \%)$ to avoid the errors associated with terminal convulsions of the animal.

The removed stomach was incised in $40 \mathrm{ml}$ of $\mathrm{NaOH}$ solution $(0.1 \mathrm{~N})$ and its content was dissolved. One millilitter of the supernatant was added to $2 \mathrm{ml}$ of trichloroacetic acid solution $(7.5 \% \mathrm{w} / \mathrm{v})$ to precipitate the proteins. After centrifugation $(2500 \times \mathrm{g}$ for $15 \mathrm{~min}), 1 \mathrm{ml}$ of the supernatant was added to $1 \mathrm{ml}$ of $\mathrm{NaOH}(1 \mathrm{~N})$ to develop the maximum intensity of the color. The absorbance at $560 \mathrm{~nm}$ of the solution was then measured with a spectrophotometer (U-1080; Hitachi, Ltd., Tokyo).

The gastric emptying (G.E.) for each rat was calculated according to the following formula:

G.E. $(\%)=\{1-$ (Amount of phenol red recovered from the test stomach)/(Average amount of phenol red recovered from the standard stomach) $\} \times 100$

\section{Small intestinal propulsion}

The small intestinal propulsion was determined according to the reported procecedure (12). The animals were deprived of food $24 \mathrm{hr}$ prior to the experiment but allowed free access to water until $3 \mathrm{hr}$ before the experiment. A suspension of $10 \%(\mathrm{w} / \mathrm{v})$ charcoal in aqueous Arabic gum $(5 \% \mathrm{w} / \mathrm{v})$ was used as a test meal. The test drug was administered p.o. $1 \mathrm{hr}$ before the test meal was given. Ten minutes after the test meal was given, the animals were sacrificed by cervical dislocation. The small intestine was then exposed by laparotomy and the percentage traverse of charcoal meal in the small intestine was determined.

\section{Proximal colonic propulsion}

The proximal colonic propulsion was determined with a slight modification of the reported method (13). Each animal was anesthetized with pentobarbital sodium (50 $\mathrm{mg} / \mathrm{kg}$, i.p.), and the cecum was exposed by laparotomy. A vinyl tube of $1 \mathrm{~mm}$ in diameter was inserted into the cecum at the beginning of the colon. The other end of the tube was then taken out of the back. The animals were kept in individual cages for 4 to 5 days and deprived of food $24 \mathrm{hr}$ prior to the experiment.

In the experiment examining the proximal colonic propulsion, a suspension of $5 \%(\mathrm{w} / \mathrm{v})$ charcoal in aqueous Arabic gum (10\% w/v) was used as a test meal. Each animal was lightly anesthetized with ether and administered $0.5 \mathrm{ml}$ of the test meal into the colonic tubing. The test drug was administered p.o. $1 \mathrm{hr}$ before the test meal was given. One hour after the test meal were given, the animals were sacrificed by cervical dislocation. The colon was then exposed by laparotomy, and the percentage traverse of charcoal meal in the colon was determined.

\section{Distal colonic propulsion}

The distal colonic propulsion was determined with the procedure reported previously (14). Each animal was lightly anesthetized with ether, and a teflon ball of $3 \mathrm{~mm}$ in diameter was inserted into the colon $3 \mathrm{~cm}$ proximal to the anus. The test drug was administered p.o. $1 \mathrm{hr}$ before the teflon ball was inserted. The time required to evacuate the teflon ball was determined as an index of the distal colonic propulsion.

\section{Statistical analyses}

The result is expressed as the mean \pm S.E.M. Differences between the mean values in each drug treatment group and control group were analyzed by the Steel multiple comparison test following the Kruskal-Wallis test. A $P$ value of less than 0.05 was considered statistically significant. 


\section{RESULTS}

Effects of drugs on the gastric emptying

$\mathrm{KW}-5092$ at 1 to $30 \mathrm{mg} / \mathrm{kg}$, p.o. dose-dependently enhanced the gastric emptying and significantly enhanced it at 10 and $30 \mathrm{mg} / \mathrm{kg}$, p.o. (Fig. 1A). Metoclopramide at 0.03 to $1 \mathrm{mg} / \mathrm{kg}$, p.o. also dose-dependently enhanced the gastric emptying and significantly enhanced it at 0.3 and $1 \mathrm{mg} / \mathrm{kg}$, p.o. (Fig. 1B). On the other hand, neostigmine significantly delayed the gastric emptying at $10 \mathrm{mg} / \mathrm{kg}$, p.o. (Fig. 1C).
A

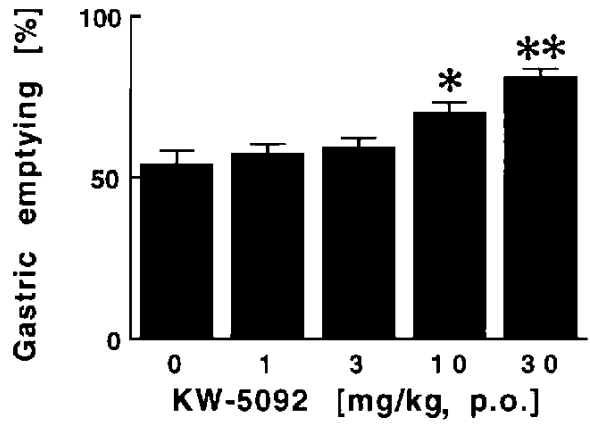

B

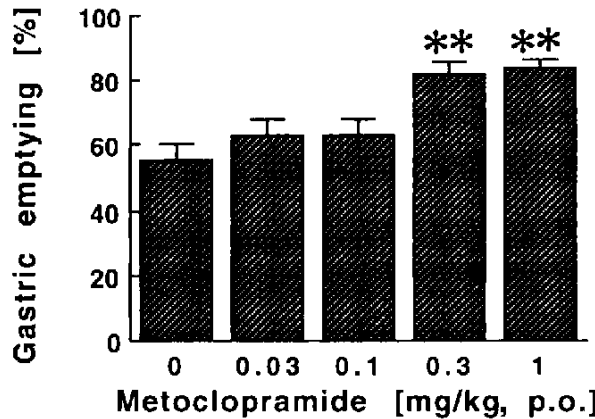

C

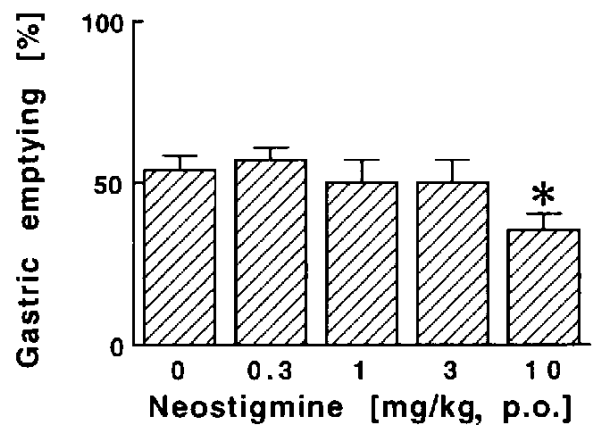

Fig. 1. Effects of KW-5092, metoclopramide and neostigmine on the gastric emptying in rats, Each bar represents the mean士S.E.M. of 10 rats. ${ }^{*}: \mathrm{P}<0.05,{ }^{* *}: \mathrm{P}<0.01$, compared with the value in the control $(0 \mathrm{mg} / \mathrm{kg}, \mathrm{p} . \mathrm{o}$ ) group (Steel multiple comparison test).
Effects of drugs on the small intestinal propulsion

KW-5092 at 1 to $30 \mathrm{mg} / \mathrm{kg}$, p.o. dose-dependently enhanced the small intestinal propulsion; and at 10 and 30 $\mathrm{mg} / \mathrm{kg}$, p.o., the effect was statistically significant (Fig. 2A). Neostigmine at 0.3 to $10 \mathrm{mg} / \mathrm{kg}$, p.o. also dose-dependently enhanced the small intestinal propulsion and significantly enhanced it at 3 and $10 \mathrm{mg} / \mathrm{kg}$, p.o. (Fig. 2C). In contrast, metoclopramide at up to $100 \mathrm{mg} / \mathrm{kg}$, p.o. did not affect the propulsion (Fig. 2B).
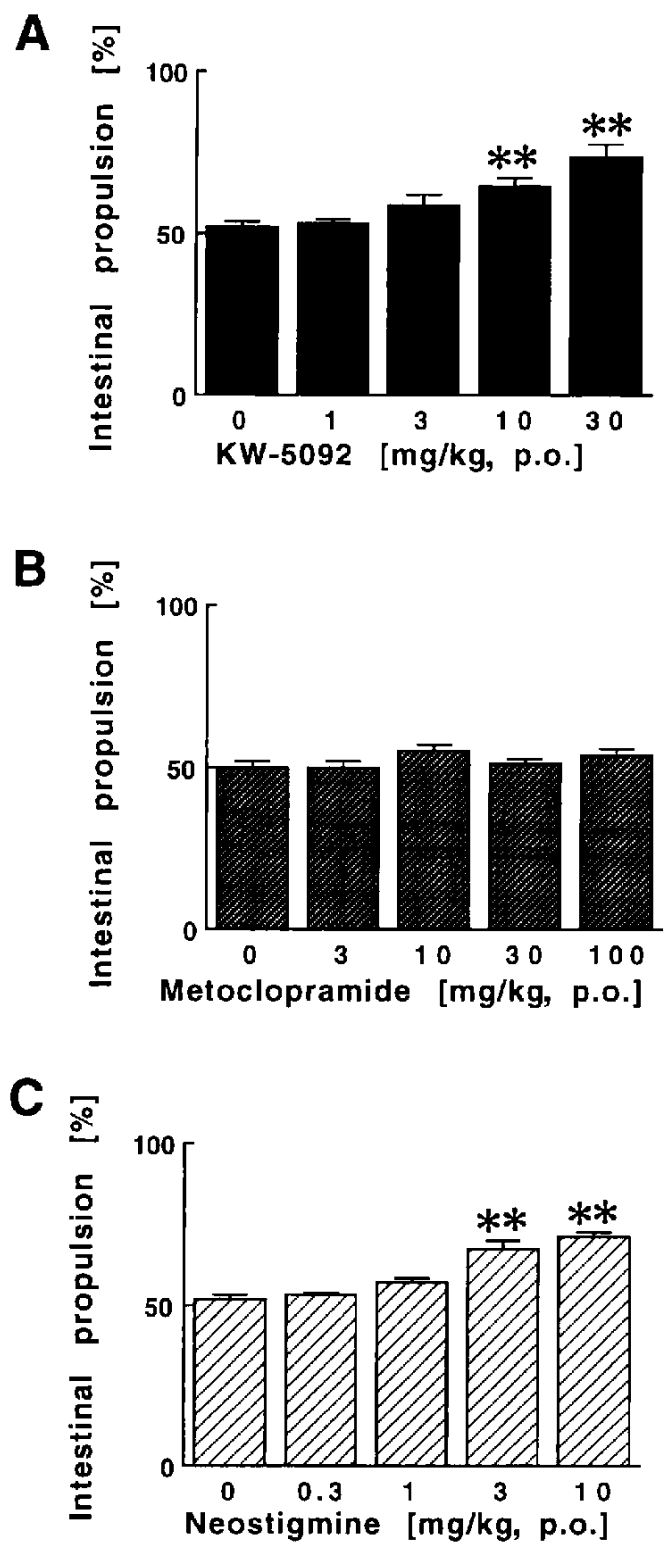

Fig. 2. Effects of KW-5092, metoclopramide and neostigmine on the small intestinal propulsion in rats. Each bar represents the mean \pm S.E.M. of 8 rats. ${ }^{* *}: \mathrm{P}<0.01$, compared with the value in the control $(0 \mathrm{mg} / \mathrm{kg}$, p.o.) group (Steel multiple comparison test). 


\section{Effects of drugs on the proximal colonic propulsion}

$\mathrm{KW}-5092$ at 1 to $30 \mathrm{mg} / \mathrm{kg}$, p.o. dose-dependently enhanced the small proximal colonic propulsion and significantly enhanced it at 3 to $30 \mathrm{mg} / \mathrm{kg}$, p.o. (Fig. 3A). Neostigmine at 0.3 to $10 \mathrm{mg} / \mathrm{kg}, \mathrm{p} . \mathrm{o}$. also dose-dependently enhanced the proximal colonic propulsion, and a significant effect was observed at $10 \mathrm{mg} / \mathrm{kg}$, p.o. (Fig. 3C). On the other hand, metoclopramide at 3 to $100 \mathrm{mg} / \mathrm{kg}$, p.o. did not affect the proximal colonic propulsion (Fig. 3B).

A

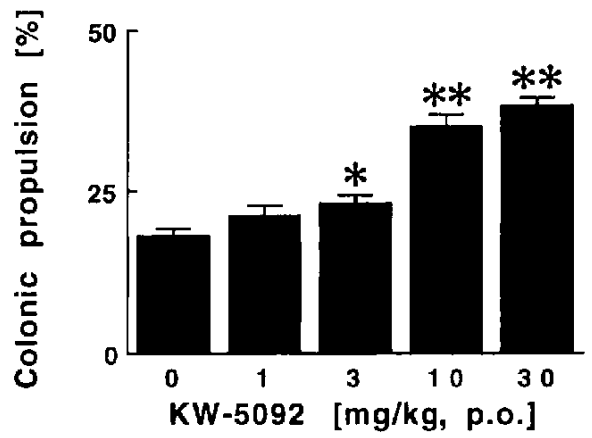

B

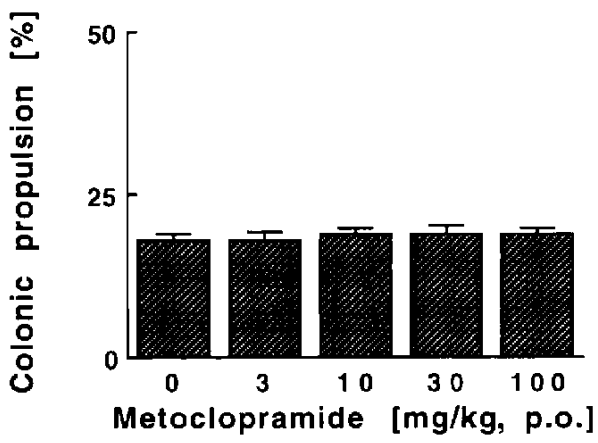

C

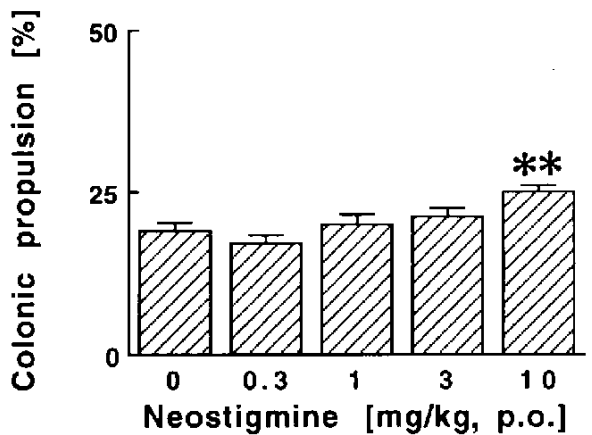

Fig. 3. Effects of KW-5092, metoclopramide and neostigmine on the proximal colonic propulsion in rats. Each bar represents the mean \pm S.E.M. of 12 rats. ${ }^{*}$ : $\mathrm{P}<0.05,{ }^{* *}$ : $\mathrm{P}<0.01$, compared with the value in the control $(0 \mathrm{mg} / \mathrm{kg}, \mathrm{p} . \mathrm{o}$.) group (Steel multiple comparison test).

\section{Effects of drugs on the distal colonic propulsion}

$\mathrm{KW}-5092$ at 1 to $30 \mathrm{mg} / \mathrm{kg}$, p.o. dose-dependently decreased the time required to evacuate the teflon ball; and at 10 and $30 \mathrm{mg} / \mathrm{kg}$, p.o., the effect was statistically significant (Fig. 4A). Neostigmine at 0.3 to $10 \mathrm{mg} / \mathrm{kg}$, p.o. also dose-dependently decreased the time required to evacuate the teflon ball and significantly decreased it at $10 \mathrm{mg} / \mathrm{kg}$, p.o. (Fig. 4C). In contrast, metoclopramide at 3 to $100 \mathrm{mg} / \mathrm{kg}$, p.o. did not affect the distal colonic propulsion (Fig. 4B).

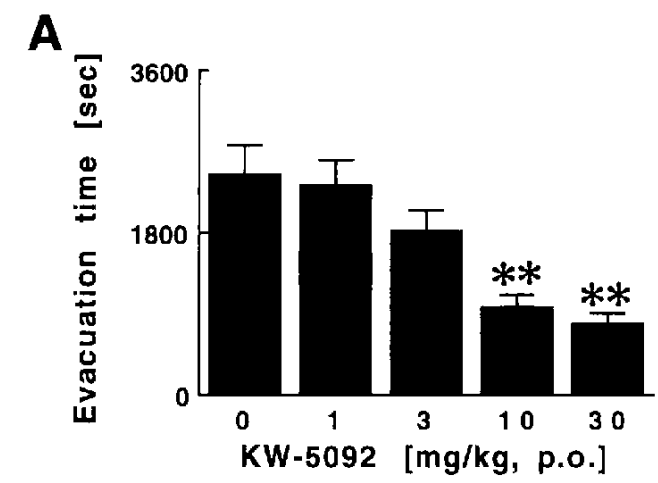

B
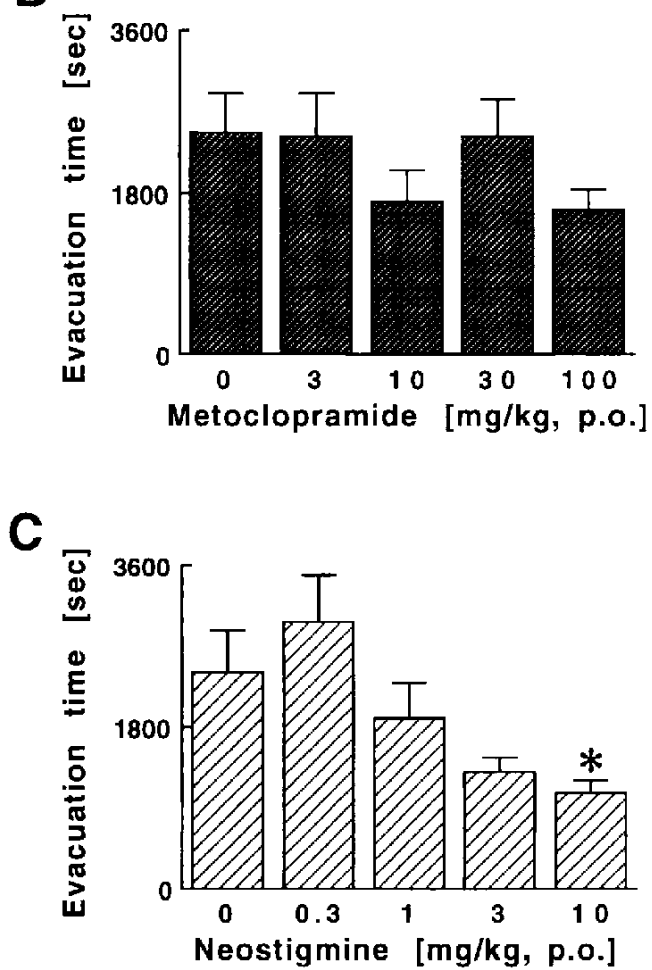

Fig. 4. Effects of KW-5092, metoclopramide and neostigmine on the distal colonic propulsion in rats. Each bar represents the mean \pm S.E.M. of 12 rats. ${ }^{*}: \mathrm{P}<0.05,{ }^{* *}: \mathrm{P}<0.01$, compared with the value in the control $(0 \mathrm{mg} / \mathrm{kg}$, p.o.) group (Steel multiple comparison test). 


\section{DISCUSSION}

The present study demonstrated that KW-5092 enhanced all the types of GI propulsion examined, from the stomach to the colon, in rats. In fact, KW-5092 is known to enhance the GI motility from the stomach to the colon in dogs (9). Taken together, it is reasonable to assume that the enhanced GI motility by KW-5092 can accompany the accelerated GI propulsion. On the other hand, metoclopramide enhanced only the gastric emptying, while neostigmine enhanced the small intestinal and the colonic propulsion but delayed the gastric emptying. Indeed, the inhibitory effect of neostigmine on the gastric emptying was also observed in horses (15). Thus, neostigmine seems to inhibit the gastric emptying, whereas this drug enhances the motility of the stomach as well as those of the lower GI tract (9). The inhibitory effect of neostigmine on the gastric emptying may be due to the inability of this drug to promote the gastroduodenal coordination. In any case, the present results suggest that KW-5092, unlike metoclopramide or neostigmine, may be a novel gastroprokinetic drug effective in a wide range from the stomach to the colon.

In the present study, metoclopramide, which is known to release $\mathrm{ACh}(4,5)$, enhanced only the upper GI propulsion while neostigmine, an AChE inhibitor (6), enhanced only the lower GI propulsion in rats. These results are in accordance with the previous ones that metoclopramide enhances only the gastric and the duodenal GI motor activity in conscious dogs (16) and that neostigmine increases the colonic GI motility in horses (17). These observations as well as ours suggest that the enhanced propulsion and motor activity of the upper gut are mainly associated with the $A C h$ release facilitation and that those of the lower gut are mainly associated with the AChE inhibition. The regional difference in the sensitivity between the ACh release facilitator and the AChE inhibitor may be due to the heterogeneity of cholinergic innervation and AChE distribution. Further studies, however, are required to clarify this point. KW-5092 inhibits AChE (8) and facilitates $\mathrm{ACh}$ release from the isolated intestine (11) at similar concentrations. Thus, the combined effect of $\mathrm{AChE}$ inhibition and ACh release facilitation seems to be involved in the enhancement by KW-5092 of the propulsion as well as the motor activity in a wide range of the gut. In fact, the combination of neostigmine $(10 \mathrm{mg} / \mathrm{kg}$, p.o.) and metoclopramide ( $1 \mathrm{mg} / \mathrm{kg}$, p.o.) enhanced both the gastric emptying and the distal colonic propulsion in rats (N. Kishibayashi et al., unpublished observation).

In addition to metoclopramide, other gastroprokinetic agents, such as domperidone (18) and cisapride (19), have been effectively used for treatment of GI motility dysfunctions associated with gastric stasis, gastroparesis or gas- troesophageal reflux disease. Domperidone enhances gastroduodenal coordination via blockade of a specific dopamine receptor (18) and enhances only the antral and the duodenal motor activity in conscious dogs (20). On the other hand, cisapride enhances $\mathrm{ACh}$ release without affecting dopamine receptors (19) and enhances the GI motor activity from the gastric antrum to the colon in conscious dogs (15). The stimulating effect by cisapride of the GI motor activity has been ascribed to its ACh release facilitation (19), although the precise mechanism involved remains obscure. In rats, however, cisapride enhances the gastric emptying but does not stimulate the intestinal or the colonic propulsion (N. Kishibayashi et al., unpublished observation). In contrast, KW-5092 enhances the propulsion and the motor activity in a wide range of the GI tract not only in dogs (9) but also in rats (this study). Moreover, KW-5092, but not cisapride, ameliorated the colonic propulsion delayed by clonidine or loperamide in rats (21). KW-5092 could thus be a gastroprokinetic drug of a novel type that may be a possible treatment for a variety of GI motility dysfunctions.

In conclusion, the present study demonstrates that KW-5092 enhances the GI propulsion in a wide range from the stomach to the colon, whereas metoclopramide enhances only the upper GI propulsion, and neostigmine enhances only the lower GI propulsion. KW-5092 may be a useful drug for the treatment of the GI motility dysfunctions not only in the upper but also in the lower GI tract.

\section{Acknowledgments}

We wish to thank S. Sasho for preparation of KW-5092 and thank Drs. A. Ishii and T. Hirata for encouragement and support.

\section{REFERENCES}

1 Albibi R and McCallum RW: Metoclopramide: Pharmacology and clinical application. Ann Intern Med 98, 86- 95 (1983)

2 Zar MA, Ebon OO and Bateman DN: Effect of metoclopramide in guinea pig ileum longitudinal muscle: evidence against dopamine mediation. Gut 23, 66-70 (1982)

3 Costall B, Naylor RJ and Tan CCW: Neuronally mediated contraction responses of guinea pig stomach smooth muscle preparations: modification by benzamide derivatives does not reflect a dopamine antagonist action. Eur J Pharmacol 102, 79-89 (1984)

4 Buchheit KH, Costall B, Engel G, Gunning SJ, Naylar RJ and Richardson BP: 5-Hydroxytryptamine receptor antagonism by metoclopramide and ICS 205-930 in guinea-pig leads to enhancement of contractions of smooth muscle strips induced by electrical field stimulation and facilitation of gastric emptying in vivo. J Pharm Pharmacol 37, 664-667 (1985)

5 Sanger GJ: Activation of a myenteric 5-hydroxytryptamine-like receptor by metoclopramide. J Pharm Pharmacol 39, 449-453 (1987)

6 Atack JR, Yu Q-S, Soncrant TT, Brossi A and Rapoport SI: Comparative inhibitory effects of various physostigmine ana- 
logs against acetyl- and butyrylcholinesterases. J Pharmacol Exp Ther 249, 194-202 (1989)

7 Sasaki D, Kido A and Yoshida Y: Effect of antispasmodic drugs on the colonic motility part II: clinical study in man. Int $J$ Clin Pharmacol Ther Toxicol 22, 338-341 (1984)

8 Sasho $\mathrm{S}$, Obase $\mathrm{H}$, Ichikawa $\mathrm{S}$, Kitazawa $\mathrm{T}$, Nonaka $\mathrm{H}$, Yoshizaki R, Ishii A and Shuto K: Synthesis of 2-imidazolidinylidenepropanedinitrile derivatives as stimulators of gastrointestinal motility. J Med Chem 36, 572-579 (1993)

9 Kishibayashi N, Tomaru A, Ichikawa S, Kitazawa T, Shuto K, Ishii $\mathrm{A}$ and Karasawa $\mathrm{A}$ : Enhancement by KW-5092, a novel gastroprokinetic agent, of the gastrointestinal motor activity in dogs. Jpn J Pharmacol 65, 131 - 142 (1994)

10 Kishibayashi N, Ishii A and Karasawa A: Enhancement by KW5092, a novel gastroprokinetic agent, of the release of acetylcholine from enteric neurons in guinea pig ileum. Jpn J Pharmacol 64, 289-295 (1994)

11 Scarpigno C, Capovilla $T$ and Bertaccini G: Action of caerulein on gastric emptying of the conscious rat. Arch Int Pharmacodyn Ther 246, 286-294 (1980)

12 Megens AAHP, Canters LLJ, Awouters FHL and Niemegeers CJE: Is in vivo dissociation between the antipropulsive and antidiarrheal properties of opioids in rats related to gut selectivity? Arch Int Pharmacodyn Ther 298, 220-229 (1989)

13 Ueda M, Matsuda S, Kawakami S, Mineshita $\mathrm{T}$ and Takeda $\mathrm{H}$ : On the propulsive motility of large intestine of mice and effects of pharmacological agents on it. Oyo-Yakuri/Pharmacometrics 3, 265-294 (1969) (Abstr in English)

14 Yamada $\mathrm{K}$ and Onoda Y: Effects of trimebutine on colonic propulsion in mice. J Smooth Muscle Res 28, 87-93 (1992)

15 Adams SB and MacHarg MA: Neostigmine metylsulfate delays gastric emptying of particulate markers in horses. Am J Vet Res 46, 2498-2499 (1985)

16 Yoshida N, Ito T, Karasawa T and Itoh Z: AS-4370, a new gastrokinetic agent, enhances upper gastrointestinal motor activity in conscious dogs. J Pharmacol Exp Ther 257, 781-787 (1991)

17 Adams SB, Lamar CH and Masty J: Motility of the distal portion of the jejunum and pelvic flexure in ponies: Effects of six drugs. Am J Vet Res 45, $795-799$ (1984)

18 Brogden RN, Carmine AA, Heel RC, Speight TM and Avery GS: Domperidone. Drugs 24, 360-400 (1982)

19 McCallum RW, Parakash C, Campoli-Richards DM and Goa KL: Cisapride. Drugs 36, 652-681 (1988)

20 Iwanaga Y, Mitashita N, Morikawa K, Mizumoto A, Kondo Y and Itoh $\mathrm{Z}$ : A novel water-soluble dopamine-2 antagonist with anticholinesterase activity in gastrointestinal motor activity. Comparison with domperidone and neostigmine. Gastoenterology 99, $401-408$ (1988)

21 Takasaki K, Kishibayashi N, Ishii A and Karasawa A: Effects of KW-5092, a novel gastroprokinetic agent, on the delayed colonic propulsion in rats. Jpn J Pharmacol 65, 67-71 (1994) 